\title{
Augmented reality for $n$ Dimensional building information modelling contextualization, customization and curation
}

Conference or Workshop Item

Accepted Version

Lee, X. S., Khamidi, M. F., See, Z. S., Lees, T. and Chai, C. S. (2017) Augmented reality for nDimensional building information modelling contextualization, customization and curation. In: 22nd International Conference on Virtual Systems \& Multimedia (VSMM 2016), October 17-21, 2016, Kuala Lumpur. Available at http://centaur.reading.ac.uk/69783/

It is advisable to refer to the publisher's version if you intend to cite from the work. See Guidance on citing.

Published version at: http://doi.org/10.1109/VSMM.2016.7863152

All outputs in CentAUR are protected by Intellectual Property Rights law, 
including copyright law. Copyright and IPR is retained by the creators or other copyright holders. Terms and conditions for use of this material are defined in the End User Agreement.

\section{www.reading.ac.uk/centaur}

\section{CentAUR}

Central Archive at the University of Reading

Reading's research outputs online 


\title{
Augmented Reality for nDimensional Building Information Modelling
}

\author{
Contextualization, Customization and Curation
}

\author{
XIA SHENG LEE, MOHD FARIS KHAMIDI \\ School of Built Environment \\ University of Reading Malaysia \\ Educity, Iskandar Puteri, Johor, Malaysia. \\ x.s.lee@reading.edu.my, m.f.khamidi@reading.edu.my
}

TIM JOHN LEES

\author{
School of Construction Management and Engineering \\ University of Reading \\ Whiteknights, Reading Berkshire, United Kingdom. \\ t.j.lees@ reading.ac.uk
}

\begin{abstract}
This paper presents an experimental method and apparatus of augmented reality (AR) for nDimensional (nD) building information modeling (BIM). BIM allows nD information to be visualized simultaneously by architects, engineers and constructors to gain a synchronized understanding viewing from different perspectives. However, BIM is conventionally being operated on a desktop-based computer which makes collaboration less flexible, and it also creates an isolation gap between the model and reality. This isolation gap does not severely affect experienced and skilled professionals, as they can bridge the isolation gap with their intuition developed over the years. Nevertheless, users who are lack of such experience will feel the isolation gap between the digital realm and practicable reality, which could be the hurdle in project participation and decision making. AR allows virtual content to be mixed with real environment for user experience. In the context of our study, $A R$ is functional to present the $\mathrm{nD}$ information of BIM, at the same time retaining users' connection with the reality. It is not just being utilized solely for presentation, but also to maximize the potential for communication, interaction and experience. This pilot study investigates effective technological approach of using AR as an effective collaboration technology combining with BIM through proposed key aspects of contextualization, customization and curation. Contextualization is significant to enable users to understand the AR content by making the presented information meaningful to the target audience, implemented thru the means of 2D annotations, animations and options comparison. This study compares both AR BIM with and without contextualization. Customization can generate unique virtual environment and content for different level of users tailored to their needs and preference to create intuitive interaction with $A R$ BIM. Curation is crucial to provide users with a reliable experience, and to formulate a continually improving AR BIM thru log data and users' feedback. All in all, this paper explores the major aspects of contextualization, customization and curation, to distinguish effective approach in the currently "free for all” AR BIM development. Finally, an implication is provided
\end{abstract}

\author{
ZI SIANG SEE \\ Centre for Research-Creation in Digital Media \\ Sunway University \\ Bandar Sunway, Selangor, Malaysia. \\ zisiangsee@sunway.edu.my
}

\author{
CHANGSAAR CHAI \\ Department of Structure and Materials \\ Faculty of Civil Engineering, Universiti Teknologi Malaysia \\ Johor, Malaysia. \\ cschai@utm.my
}

for future study in terms of balance in information sufficiency and complexity for AR BIM.

Keywords - augmented reality; building information modelling; contextualization; customization; curation

\section{INTRODUCTION}

Technology advancement in the form of "future shock" [1] is developing at an exponential speed with synergy of diverse emerging digital innovations. Collaborations among different specializations are becoming more common than before [2], as technologies that are previously enigmatic and expensive are now widely available and affordable. This paper revisits two maturing digital developments - augmented reality (AR) and building information modelling (BIM) to explore the combined application. While it is essential to review the current industrial trends, this paper imaginatively explores the combination of AR and BIM from the major aspects of contextualization, customization and curation. Users who are utilizing BIM in AR understand and appreciate the content through contextualization, undergo unique experience matching their preferences though customization, and remember and archive the content through curation. These aspects are instrumental to stimulate the adoption and implementation process leading to practical functions, instead of short-lived technological hype. This research adopted framework analysis that visualizes interviewees' preferences and opinions reacting to different types of AR BIM models. Such findings are later being scrutinized to understand each model types' strengths and weakness in contextualization, customization and curation. It is noteworthy that such research is significant to mitigate the fluctuation of technological adoption and implementation as described in Gartner's hype cycle [3]. This pilot study focuses on AR and BIM, but the applied approach is suitable for other types of digital contents. 


\section{AUgMENTED REALITY}

Augmented Reality (AR) [4] allows combination of a live real-world visual experience with virtual interactive content on computing devices [5] [6]. AR becomes widely available along with the recent advances of mobile devices with usable computing capabilities. One enabler for mobile AR is tracking technology, such as computer vision techniques for tracking off pre-defined markers or markerless images. The industrial interest and need of integrating BIM with AR which allows the physical context of each construction activity or task to be visualized has been highlighted in previous study [7] [8]. Various accessibility of augmented visualization methods allow BIM-related projects to be made available for developers and end-users at faster speed, smaller devices, and higher level of graphical details.

In this study, several graphical reproduction options of BIM-project are being experimented to gauge the usefulness of AR visualization. Markerless AR experience which allows content library to be visualized on mobile devices can be developed using AR browser systems (eg. Augment) or offline mobile applications (eg. Unity and Vuforia). Typically AR browser allows greater numbers of BIM content to be stored online and presented without any constraint of mobile storage in users' devices. However, the stability of user experiences highly relies on internet network speed. Therefore it is logical and essential to deliver a moderate amount usable details for AR objects with selective information to be presented in each context related to the BIM-based project.

\section{BUILDING INFORMATION MODELLING}

Building Information modelling (BIM) is a fresh process integrating multidimensional information [9] [10] to improvise design, construction, and facility management for the whole built environment [11]. BIM provides an efficient delivery foundation that benefits all construction industry stakeholders [12]. Such digital process makes it possible to invigorate integration between BIM with $\mathrm{AR}$ to accommodate decision making [13] by creating user-centric interface [14].

\section{DIGITAL CONTENT USER PERCEPTION AND SATISFACTION}

In this study, digital content delivery focus in contextualization is of the utmost importance [15] [16].

Contextualization is to localize the AR BIM applications by ensuring that the correct meanings of source strings are conveyed. In other words, it is giving meanings to AR BIM content, so that it is understandable. Without contextualization, users' perception and satisfaction will be hampered. It is also now much easier to provide unique contents of direct relevance to individual customer [17] by studying user perception and satisfaction [18].

Customization is defined as typically developed in response to specific order by end users. It is to personalizing AR BIM content, so that it suits specific needs. Digital contents should be managed from the curation aspects by maintaining and adding value to the content for both current and future use [19]. Generally, researchers are familiar with how to be an author, but now they have to learn how to become a digital content curator [20] [21].

Curation is about maintaining and adding value to AR BIM. It is deciding and archiving AR BIM content, so that it is usable in the future. It is an active management and appraisal of digital information over its entire life cycle [19]. In this circumstance, AR BIM is specifically developed to improve construction project management monitoring and control through combination of live real-world visual and BIM model. Therefore, it is expected to overcome project delivery hindrance such as cost overrun and delay [22].

\section{RESEARCH METHODOLOGY}

In this case study, interview and literature review are the selected methods for data collection purpose. Such methods are perfect suited to distinguish objectives that have to be complied, to accomplish the required outcomes and avoidance of any entanglement or inaccuracy of data, which will then distract the genuine intentions at the very initial phase.

During the study, the literature review is established ahead. This inevitably would link to the obtainment of much precious background knowledge regarding the arisen issues, in contemporaneous with the gaining of more detailed review to equip with the relevance outcomes to be stroke. Undoubtedly, the data is been fully utilized to outline the conceptual phase, explicate and elaborate the study's criteria.

The personal interviews are executed to generate findings for the desired objectives. This approach is best suited as the upcoming results required have to be specific and personaloriented. The interviews are directed to respective personnel of BIM-related projects; as inevitably, actual and professional perspectives and facts are highly demanded to boost the results' reliability. It is important to choose personal interview as abundant private and confidential data and information were necessitate for current research and thus, privacy and approval are decisive.

The interview sessions were carried out in September 2016. The data obtained from the interviews is transcribed and analyzed. The framework analysis [23] is used to analyze the interview data. Srivastava \& Thomson (2009) defined framework analysis as a qualitative method that is wellappropriated for applied policy research. Framework analysis is portraying satisfying performance when adapted to research that has specific questions, a limited time frame, a predesigned sample and a priori issues. During the analysis process, data is sifted, charted and sorted in parallel with key themes using five steps, which are: (1) familiarization: transcribing and reading the data, (2) identifying a thematic framework, (3) indexing/ coding: using numerical or textual codes to identify specific piece of data which correspond to different themes, (4) charting, (5) mapping and interpretation.

In this study, there are 4 types of AR BIM models: (1) texturized model (Fig. 1), (2) geometry with 2D info model 
(Fig. 2), (3) geometry only model (Fig. 3), and (4) wire frame model (Fig. 4). TABLE I list the codes for different interviewee's opinion.

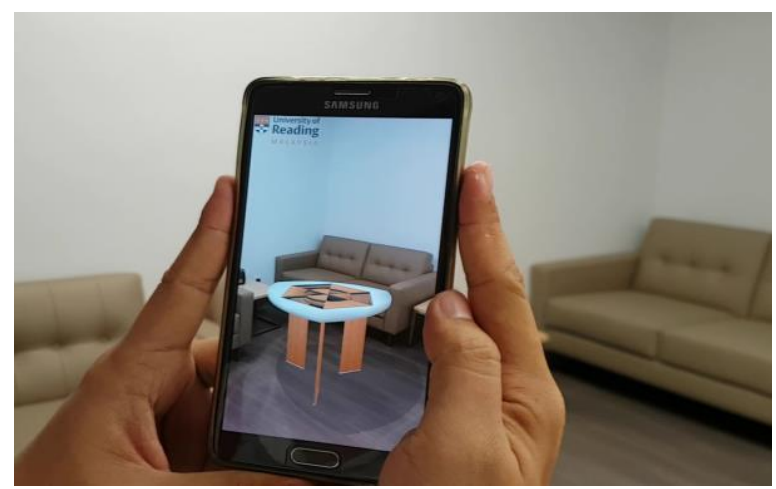

Fig. 1. Texturized model.

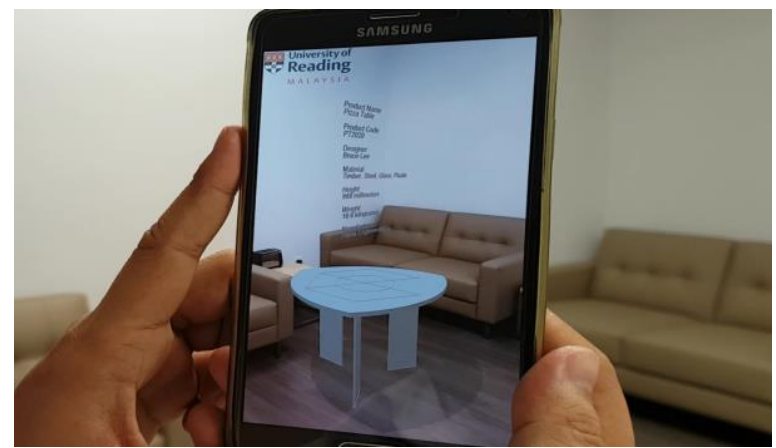

Fig. 2. Geometry with 2D info model.

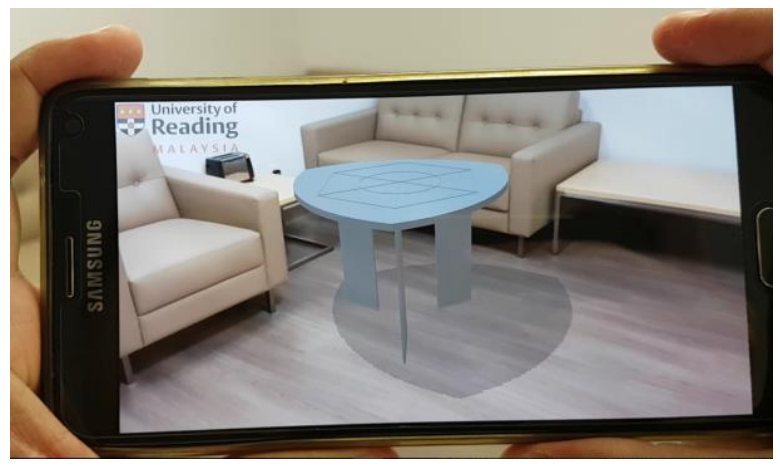

Fig. 3. Geometry only model.

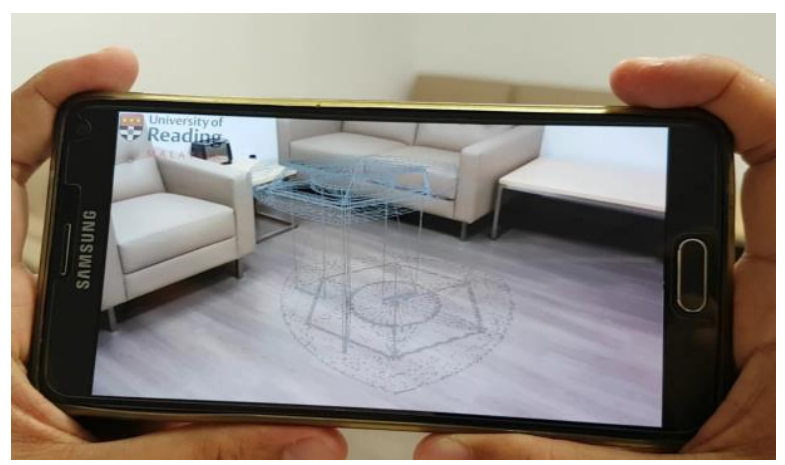

Fig. 4. Wire frame model.
TABLE I. CODE FOR INTERVIEWEE'S OPINION

\begin{tabular}{|l|l|}
\hline Code & \multicolumn{1}{|c|}{ Description of interviewee's opinion } \\
\hline C01 & Improves job quality \\
\hline C02 & Increase productivity \\
\hline C03 & Enhances effectiveness \\
\hline C04 & Increase profit \\
\hline C05 & Access more information \\
\hline C06 & Helps in decision making \\
\hline C07 & Easy to learn with it \\
\hline C08 & Interaction is clear and understandable \\
\hline C09 & Can be used without expert help \\
\hline C10 & Improve communication in organization \\
\hline C11 & I want to use it \\
\hline C12 & I like the idea of using this model \\
\hline
\end{tabular}

The data obtained from the study is transcribed and analyzed. Due to the limited numbers of interviewees that understand both AR and BIM, only acceptance percentage above $70 \%$ are considered valid. Simple data visualizations are perform to better understand the results.

\section{FINDINGS AND DiscUSSIONS}

There are five (5) architects, three (3) civil and structure engineers and one (1) each of mechanical engineer and electrical engineer participated in the interview. It is found that $70 \%$ of the interviewees are middle executive level and above, indicating a high credible of respondent profile in terms of managerial level and working experience which are salient to justify AR BIM contribution in this matter. The findings are summarized in 3 tables: (1) TABLE II. Model acceptance for contextualization, (2) TABLE III. Model acceptance for customization and (3) TABLE IV. Model acceptance for curation.

TABLE II. MODEL ACCEPTANCE FOR CONTEXTUALIZATION

\begin{tabular}{|l|c|c|c|c|}
\hline \multirow{2}{*}{ Code } & \multicolumn{4}{|c|}{ Type of Model } \\
\cline { 2 - 5 } & Texturized & $\begin{array}{c}\text { Geometry } \\
\text { With } \\
\text { 2D Info }\end{array}$ & $\begin{array}{c}\text { Geometry } \\
\text { Only }\end{array}$ & Wire Frame \\
\hline C01 & $100.0 \%$ & $100.0 \%$ & $80.0 \%$ & $50.0 \%$ \\
\hline C02 & $90.0 \%$ & $100.0 \%$ & $70.0 \%$ & $60.0 \%$ \\
\hline C03 & $100.0 \%$ & $100.0 \%$ & $70.0 \%$ & $60.0 \%$ \\
\hline C04 & $70.0 \%$ & $90.0 \%$ & $40.0 \%$ & $50.0 \%$ \\
\hline C05 & $90.0 \%$ & $100.0 \%$ & $80.0 \%$ & $60.0 \%$ \\
\hline C06 & $100.0 \%$ & $100.0 \%$ & $60.0 \%$ & $40.0 \%$ \\
\hline C07 & $90.0 \%$ & $90.0 \%$ & $80.0 \%$ & $50.0 \%$ \\
\hline C08 & $90.0 \%$ & $90.0 \%$ & $50.0 \%$ & $40.0 \%$ \\
\hline C09 & $70.0 \%$ & $80.0 \%$ & $40.0 \%$ & $40.0 \%$ \\
\hline C10 & $100.0 \%$ & $100.0 \%$ & $70.0 \%$ & $40.0 \%$ \\
\hline C11 & $100.0 \%$ & $100.0 \%$ & $60.0 \%$ & $60.0 \%$ \\
\hline C12 & $100.0 \%$ & $100.0 \%$ & $70.0 \%$ & $60.0 \%$ \\
\hline
\end{tabular}


TABLE III. MODEL ACCEPTANCE FOR CUSTOMIZATION

\begin{tabular}{|l|c|c|c|c|}
\hline \multirow{2}{*}{ Code } & \multicolumn{4}{|c|}{ Type of Model } \\
\cline { 2 - 5 } & Texturized & $\begin{array}{c}\text { Geometry } \\
\text { With } \\
\text { 2D Info }\end{array}$ & $\begin{array}{c}\text { Geometry } \\
\text { Only }\end{array}$ & Wire Frame \\
\hline C01 & $90.0 \%$ & $100.0 \%$ & $70.0 \%$ & $40.0 \%$ \\
\hline C02 & $100.0 \%$ & $100.0 \%$ & $80.0 \%$ & $50.0 \%$ \\
\hline C03 & $100.0 \%$ & $90.0 \%$ & $70.0 \%$ & $50.0 \%$ \\
\hline C04 & $100.0 \%$ & $100.0 \%$ & $60.0 \%$ & $50.0 \%$ \\
\hline C05 & $100.0 \%$ & $90.0 \%$ & $60.0 \%$ & $50.0 \%$ \\
\hline C06 & $100.0 \%$ & $100.0 \%$ & $70.0 \%$ & $50.0 \%$ \\
\hline C07 & $100.0 \%$ & $100.0 \%$ & $70.0 \%$ & $50.0 \%$ \\
\hline C08 & $100.0 \%$ & $100.0 \%$ & $70.0 \%$ & $50.0 \%$ \\
\hline C09 & $80.0 \%$ & $80.0 \%$ & $50.0 \%$ & $40.0 \%$ \\
\hline C10 & $90.0 \%$ & $80.0 \%$ & $50.0 \%$ & $50.0 \%$ \\
\hline C11 & $100.0 \%$ & $100.0 \%$ & $50.0 \%$ & $50.0 \%$ \\
\hline C12 & $100.0 \%$ & $100.0 \%$ & $60.0 \%$ & $50.0 \%$ \\
\hline
\end{tabular}

TABLE IV. MODEL ACCEPTANCE FOR CURATION

\begin{tabular}{|l|c|c|c|c|}
\hline \multirow{2}{*}{ Code } & \multicolumn{4}{|c|}{ Type of Model } \\
\cline { 2 - 5 } & Texturized & $\begin{array}{c}\text { Geometry } \\
\text { With } \\
\text { 2D Info }\end{array}$ & $\begin{array}{c}\text { Geometry } \\
\text { Only }\end{array}$ & Wire Frame \\
\hline C01 & $100.0 \%$ & $90.0 \%$ & $50.0 \%$ & $70.0 \%$ \\
\hline C02 & $100.0 \%$ & $80.0 \%$ & $50.0 \%$ & $70.0 \%$ \\
\hline C03 & $100.0 \%$ & $90.0 \%$ & $50.0 \%$ & $70.0 \%$ \\
\hline C04 & $90.0 \%$ & $80.0 \%$ & $40.0 \%$ & $60.0 \%$ \\
\hline C05 & $100.0 \%$ & $100.0 \%$ & $60.0 \%$ & $60.0 \%$ \\
\hline C06 & $100.0 \%$ & $80.0 \%$ & $60.0 \%$ & $60.0 \%$ \\
\hline C07 & $80.0 \%$ & $80.0 \%$ & $70.0 \%$ & $60.0 \%$ \\
\hline C08 & $100.0 \%$ & $80.0 \%$ & $60.0 \%$ & $60.0 \%$ \\
\hline C09 & $70.0 \%$ & $60.0 \%$ & $50.0 \%$ & $50.0 \%$ \\
\hline C10 & $100.0 \%$ & $80.0 \%$ & $60.0 \%$ & $60.0 \%$ \\
\hline C11 & $100.0 \%$ & $80.0 \%$ & $60.0 \%$ & $60.0 \%$ \\
\hline C12 & $100.0 \%$ & $80.0 \%$ & $70.0 \%$ & $50.0 \%$ \\
\hline
\end{tabular}

\section{CONCLUSION}

The findings demonstrate consistency among the interviewees' preferences. The most preferred type of model is texturized model, followed by geometry with 2D info model. These two types of models are recognized from the aspects of helping users to contextualize to customize AR BIM contents. As comparison, geometry only and wireframe models are not as widely recognized as a good AR BIM application. While this pilot study mainly focuses on construction industry professionals, it is interesting using the same models and interface to investigate other target groups based on different categories such as genders, age, expertise levels etc. The potential of AR BIM is both promising and challenging and there are great potential for a new research direction from the aspects of contextualization, customization and curation.

\section{References}

[1] A. Toffler, "Future shock", Amereon Ltd., New York, 1970.

[2] F. Wickson, A.L Carew, A.W. Russell. "Transdisciplinary research: characteristics, quandaries and quality", Futures 38, no. 9, 2006, pp. 1046-1059

[3] A. Linden, and J. Fenn, "Understanding Gartner's hype cycles", Strategic Analysis Report No R-20-1971. Gartner, Inc, 2003.

[4] R. Azuma, "A survey of augmented reality", Presence: Teleoperators and virtual environments 6, no. 4, pp. 355-385, 1997.

[5] M. Billinghurst, "The Future of Augmented Reality in Our Everyday Life", Nagoya, Japan: 19th International Display Workshops, In Proceedings of the 19th International Display Workshops, 4-7 December 2011.

[6] D. Schmalstieg, T. Langlotz, and M. Billinghurst, "Augmented Reality 2.0", Virtual Realities, Springer, pp. 13-37, 2010

[7] X. Wang, P. ED. Love, M. J. Kim, C. Park, C. Sing, and L. Hou, "A conceptual framework for integrating building information modeling with augmented reality", Automation in Construction 34 37-44, 2013.

[8] X. Wang, M. J. Kim, P. ED. Love, and S. Kang, "Augmented Reality in built environment: Classification and implications for future research", Automation in Construction 32", pp. 1-13, 2013.

[9] G. Aound, A. Lee, and S. Wu, "The utilisation of building information models in $\mathrm{nD}$ modelling: a study of data interfacing and adoption barriers", ITcon Special Issue From 3D to nD modelling, vol. 10, pp. 15$16,2004$.

[10] X. S. Lee, W. T. Cheah and M. F. Khamidi, "5D Building Information Modelling-A Practicability Review", In MATEC Web of Conferences, vol. 66, p. 00026. EDP Sciences, 2016.

[11] S. Azhar, "Building information modeling (BIM): Trends, benefits, risks, and challenges for the AEC industry", Leadership and Management in Engineering 11, no. 3, pp. 241-252, 2011.

[12] B. Succar, "Building information modelling framework: A research and delivery foundation for industry stakeholders", Automation in construction 18, no. 3, pp. 357-375, 2009.

[13] J. Schade, T. Olofsson, and M. Schreyer, "Decision-making in a model-based design process", Construction management and Economics 29, no. 4, pp. 371-382, 2011

[14] M. Olbrich, G. Holger, S. Kahn, T. Engelke, J. Keil, P. Riess, S. Webel, U. Bockholt, and G. Picinbono, "Augmented reality supporting usercentric building information management", The visual computer 29 , no. 10, pp. 1093-1105, 2013.

[15] R. Rogowski, and S. Powers, "Contextualization is the Key to Delivering Powerful, Personalized Digital Experiences", UX Magazine (uxmag.com), article no. 974, March 2013.

[16] K. Keahey, and T. Freeman, "Contextualization: Providing one-click virtual clusters", IEEE Fourth International Conference on eScience, pp. 301-308, 2008.

[17] A. Ansari, and C. F. Mela, "E-customization", Journal of marketing research 40, no. 2, pp. 131-145, 2003.

[18] J. Wind, and A. Rangaswamy, "Customerization: The next revolution in mass customization", Journal of interactive marketing 15 , no. 1, pp. 1332, 2001.

[19] M. Pennock, "Digital Curation: A life-cycle approach to managing and preserving usable digital information", Library \& Archives, January 2007.

[20] N. Beagrie, "Digital curation for science, digital libraries, and individuals." International Journal of Digital Curation 1, no. 1, pp. 3-16, 2008

[21] J. Gray, S. S. Szalay, A. R. Thakar, and C. Stoughton, "Online scientific data curation, publication, and archiving", In Astronomical Telescopes and Instrumentation, pp. 103-107. International Society for Optics and Photonics, 2002

[22] C. S. Chai, A. M. Yusof, H. Habil, "Delay mitigation in the Malaysian housing industry: A structural equation modelling approach", Journal of Construction in Developing Countries. Vol 20 (1), pp. 65-83, 2015.

[23] A. Srivastava, and S. B. Thomson. "Framework analysis: a qualitative methodology for applied policy research", 2009. 
